\title{
LA CRUZ DEL ESPACIO EUROPEO DE EDUCACIÓN SUPERIOR
}

\section{LA CRUZ DEL ESPACIO EUROPEO DE EDUCACIÓN SUPERIOR}

\author{
Felipe Trillo Alonso*
}

\begin{abstract}
RESUMEN
La creación del Espacio Europeo de Educación Superior (EEES), ha promovido numerosos cambios en la enseñanza universitaria durante los últimos años. El objetivo de este trabajo es contribuir a la definición y al debate de esos cambios mediante un posicionamiento crítico respecto: al aprendizaje autónomo, el modelo de enseñanza basado en competencias, el rol de los estudiantes y de los profesores, el papel de las Tecnologías de la Información y la Comunicación (TIC) en la interacción didáctica, la presión burocrática de la evaluación externa de la calidad, la tensión en las facultades por la redefinición de los currículos, el sentido de la formación superior (empleo versus profesionalización), y la propia autonomía universitaria frente al poder de la economía del conocimiento.

Palabras clave: Espacio Europeo de Educación Superior (EEES), aprendizaje autónomo, modelo de enseñanza basado en competencias, evaluación externa de la calidad, autonomía universitaria.
\end{abstract}

\begin{abstract}
ABTRACT
The creation of the European Higher Education Area has promoted numerous changes in university education in recent years. The aim of this paper is to contribute to the definition and discussion of these changes through a critical position, regarding: the autonomous learning, the teaching model based on competencies, the role of students and teachers, the role of the new technologies of information and communication in teaching interaction, the bureaucratic pressure of external quality assessment, the tension in the faculties by the redefinition of the curriculum, the sense of higher education (employability or professionalization), and the university's autonomy against the power of the knowledge economy.
\end{abstract}

Keywords: European Higher Education Area. Autonomous learning. Teaching model based on competencies. External quality assessment. University’s autonomy.

\section{Introducción}

-¡Qué cruz! Estábamos tan tranquilos, y de repente (por el 2003, hace de esto 5 años), toda aquella paz y mansedumbre se vio alterada por eso del EEES.
No son pocos los profesores, tampoco los estudiantes, que piensan de esta manera; que vivencian todo este proceso como una amenaza a las rutinas (no necesariamente malas) con las que se sentían cómodos. Así, salvo aquellos que confiesan estar tranquilos pues esperan que su

*Profesor titular de Didáctica y Organización Escolar de la Universidad de Santiago de Compostela. E-mail dofetria@usc.es 
jubilación o su graduación les alcance antes de empezar "de verdad" con todo esto, son muchos menos los que se animan a decirlo en voz alta, porque eso ahora no es "políticamente correcto".

Pensando específicamente en los profesores y en su pérdida de autonomía, el valor hegemónico (acrítico, preconsciente) de lo que en la universidad española define actualmente la profesionalidad docente es lo que impele a abrazar con la fe ciega del recién converso el "mensaje revelado" del EEES. La idea es esta: o estás por la labor, o no estás al día.

Y es que, como decía a 8 de enero del 2007 en el comentario al necesario libro de Juan de Pablos (Necesidades y demandas del profesorado de la Universidad de Sevilla. Universidad de Sevilla, 2006), tengo para mí que todo esto del EEES se ha convertido en una especie de tótem: emblema supuestamente protector en torno al que se "establece un sistema de creencias y organización de la tribu".

Como es sabido, el tótem suele ser un ídolo ("figura de una falsa deidad a la que se da adoración") caracterizado por su soberbia y una dureza extrema que exige permanentes sacrificios.

Generalmente tal deidad resulta inescrutable para todos excepto para una casta sacerdotal (druidas, brujos, hechiceros) que reverencialmente servida por sus correspondientes acólitos se erige en la única capaz de interpretarlo.

Entre ellos construyen numerosas leyendas ("relación de sucesos que tienen más de maravillosos que de históricos o verdaderos") que ingeniosamente hilvanadas consiguen gestar un mito ("fábula, ficción alegórica") ajeno a la razón.

Culturalmente llegamos así a la metáfora del EEES como nueva religión para la tribu universitaria. Pues, recuérdese que por religión se entiende el "conjunto de creencias o dogmas acerca de la divinidad, de sentimientos de veneración y temor hacia ella, de normas morales para la conducta individual y social y de prácticas rituales, principalmente la oración y el sacrificio para darle culto".

$\mathrm{Y}$ es que, si de la anterior definición de religión eliminamos lo de la divinidad y la oración, todo lo demás es aplicable al caso. Especialmente eso del temor, pues en efecto el EEES amenaza y atenaza a los que gobiernan la universidad en primera instancia (algo se de esto) y por extensión a todos los demás, de tal forma que en ese miedo a no cumplir en fecha y forma debida (por más que las fechas y las formas se alteren sin piedad), se encuentra la explicación de la huída hacia delante que estamos viviendo en este asunto con más ofuscación ("obscuridad de la razón, que confunde las ideas"), que conciencia ("conocimiento exacto y reflexivo de las cosas").

$\mathrm{Y}$ hasta aquí, mi motivación más intima para abordar este asunto: el deseo de servir como vehículo de expresión de los que habitualmente evitan pronunciarse (la mayoría silenciosa) o bien suelen quedar excluidos de las declaraciones no ya oficiales sino convenientes al uso (la minoría hipercrítica); y hacerlo de manera tal que proporcione una visión desmitificadora y por ende inevitablemente contracultural de todo este asunto. Por si el ejemplo sirviera para explicarme mejor, diré que me viene a la memoria aquello que cantaba Vinicius de Moraes defendiendo a la samba de las críticas de los músicos más académicos: "que no peito dos desafinados tamen late un coraçao".

Por supuesto, puedo incurrir en el error de tergiversarlos e incluso de hacerlo de manera tendenciosa al arrogarme ser el intérprete de sus planteamientos; más aún si lo hago sin contar con su permiso, es decir, sin disponer en muchos casos de una información suficientemente contrastada al respecto. Soy consciente de esa posibilidad y asumo el riesgo; por eso mismo advierto que esta perspectiva es muy subjetiva.

En otro orden, son tantos los aspectos que podrían ser tratados que corro el peligro de dispersarme en exceso. Para intentar evitarlo, voy a echar mano de una estructura conceptual clásica de la Didáctica (al fin y al cabo soy profesor de esa área) para ir abordando los diversos problemas que identifico en relación con cada una de las dimensiones de la misma.

El núcleo básico para el análisis son los procesos de enseñanza-aprendizaje regulados por el currículo que llevan a cabo estudiantes y profesores en el marco de una institución que, a su vez, se encuentra ubicada en un sistema educativo que le condiciona y que es el propio de una determinada sociedad. 
La razón que justifica un planteamiento tan amplio es que las mismas propuestas asociadas a la creación del EEES fueron, desde su inicio, extremadamente ambiciosas pues pretendieron cambiar al mismo tiempo tanto los planes de estudio como los procesos de enseñanza y aprendizaje redefiniendo los roles de profesores y estudiantes, lo que deviene en una transformación de la estructura misma de las universidades. Todo lo cual, por cierto, está bien y está mal: bien, porque intenta evitar que algún aspecto no abordado pueda actuar como lastre del proceso de cambio; mal, porque quizás el empeño resulte excesivo por inabarcable y traumático.

Empecemos pues con las preguntas, desde lo más nuclear hasta lo más amplio:

\section{¿Qué pasa con el Aprendizaje? ¿Cómo se entiende?}

Para mí la idea del aprendizaje Autónomo es la innovación educativa más relevante de todas estas iniciativas. Se trata de cambiar el estudiar para el examen y el trabajar para la nota, por la motivación intrínseca, el afán por comprender y el compromiso con la tarea de reconstrucción crítica del conocimiento mediante la atribución de sentido del que cabe emerja un pensamiento divergente (lo que no quiere decir acertado). Hablamos pues de desarrollar las capacidades de autorregulación y de metacognición en el aprendizaje; de promover procesos conducentes a relacionar la información entrante con la experiencia previa a fin de extraer significados personales; de interpelar al conocimiento y contextualizarlo; de formular hipótesis, hacer inferencias y contrastarlas mediante el análisis de las evidencias; de tomar decisiones argumentadas y ensayar alternativas para resolver problemas en contextos de incertidumbre; y de autoevaluar los resultados. Hablamos, en suma de una manera razonable de aprender que se asemeja en todo al modo como actúan los mejores profesionales de los distintos campos de conocimiento.

Pero, a mi me parece que la vocación pedagógica está muy relajada y que el compromiso de la mayoría del profesorado no está por la promoción del aprendizaje autónomo salvo que se entienda éste como un: "ahora márchese y no vuelva hasta que lo sepa"; que tiene que ver con el ya célebre chascarrillo sobre el significado del acrónimo ECTS como "Estudia Cabrón Tu Sólo".

Debiera quedar claro pues que la autonomía no es sinónima de abandonarlo a su suerte. Pese a que, por lo general, en los Libros Blancos, incluso en el de Pedagogía (que se supone que algo sabemos de esto), la perspectiva es mucho más restrictiva que la expuesta por mí aunque coincidente:

Autonomía en el aprendizaje: capacidad de orientar su estudio y aprendizaje de modo cada vez más independiente, desarrollando iniciativa y responsabilidad.

Elementos: desarrollo de su capacidad de autonomía personal, académica y profesional, capacidad de gestionar su tiempo, seleccionar sus prioridades, cumplir los plazos establecidos, responsabilidad ante lo acordado. Cuestiona las cosas por sí mismo y abandona progresivamente la dependencia de otros. (ANECA,2004).

En cualquier caso, justo es reconocer el encomiable empeño que se ha llevado a cabo en todas las universidades españolas para actualizar al personal docente en relación con esta nueva propuesta sobre el aprendizaje autónomo. Ahora bien, una cosa es admitir que se está realizando un esfuerzo y otra presuponer que ya todos saben lo que hay que hacer y, por tanto, que el próximo curso 2009/10, promover ese aprendizaje autónomo será el criterio mayoritariamente compartido por el profesorado para guiar su actividad docente.

En estas circunstancias, tengo para mí que ver el vaso medio lleno en vez de bastante vacío nos abocará irremediablemente al fracaso que conlleva la adopción meramente nominal y burocrática de un término que se entiende regular y se asume poco; un fracaso similar al que supuso la implementación por Decreto del modelo constructivista con la LOGSE en cuyo marco, por ejemplo, aún son inmensa mayoría los profesores de matemáticas de la ESO $\mathrm{y}$ el Bachillerato que no saben y en cualquier caso no practican la resolución de problemas con sus alumnos, sometiéndolos a innúmeros ejercicios de resolución meramente algorítmica.

\section{¿Qué pasa con la Enseñanza? ¿Cómo se entiende?}

La razón de ser de la enseñanza es promover el aprendizaje. A partir de ahí, y suponiendo que 
estuviéramos de acuerdo con lo dicho antes sobre el aprendizaje autónomo -lo que ya es mucho suponer-, no hay duda respecto a que su desarrollo conlleva una profunda revisión de la metodología de enseñanza al uso y que exige de los profesores un esfuerzo encomiable por actualizarse en sus competencias docentes; siendo así, y al margen de que proliferen cursos por doquier más o menos sensatos u oportunistas, realmente el dilema es si los profesores conocen, entienden y asumen esta propuesta o si la desconocen y rechazan. ¿Cuántos hay de cada grupo? No lo se. Que cada uno eche sus cuentas.

De lo que no tengo dudas es que hoy por hoy -claro que quien sabe cambia todo de este curso para el siguiente-, aún persisten formas de enseñar y de tratar a los estudiantes simplemente infumables. Me refiero: al abuso de una metodología expositiva (no magistral, que es otra cosa); al abuso de un acceso al conocimiento mediante apuntes fotocopiados que deben ser memorizados sin apenas comprender para después reproducir literalmente en exámenes tipo prueba objetiva (mal hecha) o de respuesta corta; al abuso de unas tutorías (cuyo horario se incumple las más de las veces) y que en un clima hostil sirven sólo para revisar exámenes en un regateo sobre la calificación; o lo que es tan malo, al abuso de una suerte de compadreo que sacraliza la opinión y premia al ideológicamente afín. Hay tantas perversiones posibles. Y, ¿quién puede decir que en su centro no ocurren o, por lo menos, que cuando se detectan se denuncian y corrigen de inmediato?

Sin duda resta mucho por hacer - iy no sólo guías docentes! (que aunque necesarias tampoco son la panacea, sobre todo si se adoptan de manera burocrática)-; me refiero a una enseñanza centrada en el estudiante, que parta de un contrato de aprendizaje, que propicie mediante el diálogo la reconstrucción crítica del conocimiento en el aula, que afronte la resolución de problemas y la toma de decisiones como las competencias clave de cualquier formación, que adopte el trabajo cooperativo y mediante proyectos como la manera natural de hacer las cosas, que evalúe exigentemente la comprensión de lo que se estudia, que apoye a los estudiantes aprovechando el error como oportunidad para aprender y, en fin, un muy largo etcétera.
Por supuesto mentiría si dijera que no se han hecho cosas, incluso que contamos en nuestras escuelas de referencia con muchos y brillantes ejemplos dignos de ser emulados, pero en términos globales el porcentaje es bajo.

El problema añadido es que para esto de la renovación de la metodología docente en la universidad ya hubo tiempos mejores. Y me pregunto: ¿es sólo una sensación mía sin fundamento alguno o con el cambio al Ministerio de Ciencia e Investigación se ha vuelto a poner el énfasis en la investigación en claro detrimento de la docencia (especialmente de la docencia de grado)?

\section{viven?}

\section{¿Qué ocurre con los estudiantes? ¿Cómo lo}

Alguien debería saber con rigor cuáles son sus expectativas. En primer lugar si creen que el EEES es contingente con su conducta, es decir, si consideran que lo que sea que finalmente suponga eso del EEES depende en alguna medida de lo que ellos quieren o hagan o si, por el contrario, aquello en lo que cuaje el EEES se hará tanto si quieren como si no e independientemente de sus planteamientos. En suma, si sienten esto como una oportunidad de mejora de la Universidad que de este modo se prepara para atender mejor sus necesidades y redundará en su beneficio, o si nada de eso les inquieta por ahora y tampoco les implica.

Siendo así, la verdad, no conozco estudiantes entusiasmados con la propuesta, aunque quizás existan. Sí hay un grupo muy reducido, casi marginal, que rechaza frontalmente todo esto por razones que no llego a comprender (quizás porque su argumentación no va mucho más allá de las pintadas que realizan en las paredes tipo: “ ¡Bolonia fascista!”). Así que lo que más abunda son estudiantes que se manifiestan llenos de prevención al respecto. Y siendo de ese modo concluyo que ese no es el mejor ambiente para implicarles en una reforma que teóricamente se hace pensando en ellos y para convertirlos en los principales protagonistas de su aprendizaje.

En esta línea, ante tanta euforia oficial me pregunto si no debería extrañarnos tan fría acogida por el estudiantado, que permanece al margen o incluso receloso. Me pregunto si no habremos hecho algo mal para que se haya extendido la idea 
de que todo esto es un ejemplo más de despotismo ilustrado: todo para los estudiantes pero sin ellos. Lo cual, por cierto, también cabría aplicar a buena parte del profesorado.

Específicamente sobre la predisposición de los estudiantes respecto al aprendizaje autónomo, el diagnóstico para mí está claro. Lo ignoran casi todo y están desconcertados, por tanto también recelosos. Fundamentalmente debido a que no están muy preparados. Más aún si consideramos que los hábitos de estudio más generalizados (hábitos condicionados, que conste) se orientan a la reproducción memorística de fragmentos sueltos de información, y sólo para rendir en exámenes individuales caracterizados por la naturaleza arbitraria de unas preguntas, eso sí, imprevisibles, cuya relevancia además es muy discutible.

Por supuesto hay muchas excepciones, sin duda, pero tal vez no las suficientes. $Y$ en este momento del discurso, pese a que por mi línea de investigación llevo años defendiendo el enorme potencial de aprendizaje de nuestros alumnos, no puedo evitar reconocer que su enfoque de aprendizaje es básicamente estratégico, orientado al rendimiento y que en esa dirección están cautivos de las tareas que les imponen sus profesores, pues pese a lo duro que suene, lo que funciona al fin es el instinto de supervivencia que les conmina a cambiar conductas por calificaciones.

La tarea pues que se nos plantea es ingente y tiene que ver con una evaluación educativa formativa y formadora, que haga efectivo lo que señalé antes: una enseñanza centrada en los estudiantes que promueva la capacidad de autorregulación de éstos orientándolos a la comprensión de lo que estudian.

¿Qué estamos haciendo y qué podemos hacer para entusiasmarlos con la propuesta?

Es una pregunta acuciante, más aún si tenemos en cuenta que justo cuando esto escribo (22-X-08) se ha llevado a cabo una huelga nacional de los estudiantes universitarios secundada por los de enseñanza media que, independientemente de su irregular o incluso escaso apoyo (al menos apoyo activo, pues el pasivo, esto es, el del que deja hacer porque así aprovecha para no ir a clase es mucho mayor), respondía (supuestamente) a declaraciones como estas que ha recogido la prensa:
$\mathrm{El}<<$ plan Bolonia $>>$ "supone el ataque más grave a la educación pública en los últimos veinte años y tiene como único objetivo expulsar a los hijos de los trabajadores de la universidad".

El Sindicato de Estudiantes denuncia que la implantación de los grados y postgrados provocará la privatización de la universidad además de una devaluación de las títulos, ya que para acceder a un empleo digno será necesario un postgrado.

Y claro, aunque pudiéramos estar de acuerdo con la conclusión, no es posible admitir que algo así se resuelva con una respuesta seca. tipo la de la Conselleira de Educación de la Xunta de Galicia diciendo: "non entenden".

En esto, insisto, no tenemos hechos los deberes.

\section{¿Qué ocurre con los profesores? ¿Cómo lo viven?}

La respuesta es que no lo sabemos, sobre todo si nos salimos de lo que es políticamente correcto decir. A ver, ¿hay unanimidad y si se me apura hasta entusiasmo respecto al desafío del espacio europeo, o por el contrario, lo que prima es el desconocimiento, el desconcierto o la discrepancia, junto a la indiferencia o incluso el rechazo frente a todo ese asunto?

Pues bien, ante una cuestión de este tipo lo que más me interesa destacar es el estado de ánimo de los profesores; algo fundamental para acometer cualquier actividad que requiere además un notable esfuerzo.

En esa dirección, descartados los entusiastas, que lo hay, y descartados también los cumplidores, que pese a su menor entusiasmo se esfuerzan meritoriamente por adecuarse a los criterios de la Institución, cuando pienso en la mayoría de los profesores (a partir de aquellos de los que tengo noticia), la expresión clave que en este momento lo resumiría todo es esta: se vive bajo presión.

Escribo esto a octubre de 2008 y la verdad es que han cambiado bastante las cosas en lo que va de año y, desde luego, desde que se comenzó a plantear todo esto del EEES. Si al inicio primó la indiferencia, que explicaba el desconocimiento, hoy en día ya no hay nadie que siga pensando que todo esto no le va a afectar de alguna manera (siquiera por el cambio de los planes de estudio), de manera 
que lo que prima ahora es la expectación, aunque el desconocimiento siga siendo muy grande.

Sobre la presión, se dirá que eso no es malo o incluso bueno, que convenía agitar a los profesores universitarios para que salieran de su torre de marfil y del supuesto nirvana autocomplaciente en el que se encontraban, pero no estoy de acuerdo en absoluto con esa idea, porque:

-Ni la torre es torre. Puesto que si la Universidad como institución secular ha llegado a nuestros días, superando inquisiciones y dictaduras, ha sido precisamente por su capacidad de adaptarse a los tiempos, aunque, eso sí, de acuerdo con sus propios horizontes y no con los que coyunturalmente se le pretenden imponer desde fuera;

-Ni es de marfil. Como sabemos todos los que la habitamos que cual lazarillos de Tormes nos vemos obligados a buscarnos la vida para paliar su precariedad -que siempre puede ser mayor, por supuesto, y lo es de hecho en muchos otros sitios-; sirva como ejemplo que mi dotación presupuestaria anual en mi departamento para atender la docencia de tres materias de grado, cinco grupos y trescientos alumnos, son 300 euros;

-Ni el tal nirvana existe. Y mucho menos es siesta, abulia o indolencia, por más que en la Universidad también es posible encontrar parásitos, cuentistas y hasta vagos redomados como en cualquier otro sitio, aunque si se me apura yo diría que en menor número que en otros lugares; véanse las actividades de extensión (ingentes) y las memorias "públicas" de producción científica (independientemente de que ahora se valoren como "competitivas"), pero sobre todo, ahí están las generaciones y generaciones de licenciados que, mal que bien, forman parte del tejido social de esta sociedad con el bagaje que ESTA (no otra) universidad les ha aportado

-Ni la autocomplacencia define el carácter de la mayoría. Especialmente no la que conduce a la inacción de quien se siente plenamente colmado y satisfecho. Puede haber vanidad, soberbia, engolamiento y hasta narcisismo, de esto sí que hay bastante todavía, no hay duda, pero en cualquier caso aparejada a una actividad notable o como mínimo correcta de la que sólo cabe discutir que, probablemente, no es tan sobresaliente como pretenden a veces sus artífices. En cualquier caso, si el colectivo fuera realmente tan autocomplaciente no podría entenderse tanta actividad como la que aquí realizamos.
-Ni nada, por último, resulta preferible al necesario sosiego que requiere la investigación científica, la reflexión intelectual y la comunicación docentediscente en el marco universitario. Como lo saben bien, tanto los profesores que realizan su trabajo con singular sordina, con exquisita discreción, en la casi eremita soledad de sus laboratorios, bibliotecas, despachos y trabajos de campo, como aquellos otros que, a su pesar o no, deben ir de uno a otro sitio corriendo para tratar de cumplir con sus múltiples compromisos (grupos de investigación, congresos, conferencias, agencias varias en las que son reclamados, etc.).

En cualquier caso, insisto, se vive bajo presión: la presión de la evaluación, y la presión de la burocracia; además de la presión misma de las sucesivas reformas.

\section{La presión de la evaluación:}

$\mathrm{Y}$ es que todos estos cambios comenzaron de hecho con la presión de la evaluación. Intentaré explicarlo o al menos dar mi versión sobre este asunto. En esa dirección, lo que destacaría es lo siguiente:

Que hay dos tradiciones en materia de evaluación de centros y de profesores: una preocupada por la eficacia y orientada al control y al rendimiento de cuentas, que sirve para premiar o sancionar; y otra orientada al "desarrollo institucional y profesional", que sirve para ayudar a mejorar.

Y que lo que ocurrió es que esta segunda intención formativa, claramente norteadora -al menos al inicio- del Plan Nacional de Evaluación de la Calidad de las Universidades de 1995, fue reemplazada por la primera, netamente acreditativa, cuando la ANECA asumió sus funciones en el 2002, y desarroollo el tumor que supuso el Real Decreto de 1989 sobre los quinquenios de docencia y los sexenios de investigación.

En consecuencia, se perdió la oportunidad de que la evaluación respondiese a una intención formativa, que es la que de verdad incrementa la autonomía y que supone una ayuda para los centros y los profesores: generalmente concretada en acciones que contribuyen a mejorar su organización y la calidad de los procesos de enseñanza, como son detectar necesidades y contribuír a su satisfacción 
proporcionado recursos o llevando a cabo programas de perfeccionamento profesional, etc. Que son cosas que se están haciendo, sin duda, pero en mi opinión de una manera forzada, casi vegetativa $y$, desde luego, siempre varios pasos por detrás de lo que conlleva la adopción de la otra alternativa.

Pues, en efecto, lo que se va imponiendo es la iniciativa que responde a una intención sumativa (de acreditación), que incrementa el control y supone una amenaza para los centros y los profesores: generalmente expresada mediante decisiones administrativas del tipo de promocionar a los profesores o de proceder a la revisión de sus salarios mediante un sistema que distribuye distinciones y sanciones, y que en relación a los centros lo que hace es dotarlos con más o menos medios o, por ejemplo, habilitarlos o no para desempeñar determinadas funciones. Recuérdese en este sentido cuáles postgrados se aprobaron en aquellas primera hornadas ahora necesariamente revisables, y considérese lo que ocurre ahora respecto a la posibilidad de impartir determinadas titulaciones de grado o de postgrado.

Pero ciñéndonos a lo que ocurre con los profesores, que son nuestro objeto de reflexión en este apartado, y al objeto de estimar si es razonable mi denuncia sobre la presión que la evaluación ejerce sobre ellos, añado:

a) Realmente, la realización de los planes nacionales de evaluación de las titulaciones representó para muchos de los que participaron más activamente la inevitable obligación de enfrentarse individual y colectivamente a los propios fantasmas ( a las cosas que se hacen mal) y encajar el resultado; por más que, según en qué centros, se actuase con más o menos rigor y sentido autocrítico.

b) Independientemente de que yo niegue la mayor y rechace esta práctica, el hecho de que a diferencia de los sexenios por la actividad investigadora los quinquenios por la actividad docente se concediesen prácticamente a todo el mundo dio lugar a una mayor desconsideración de la misma, especialmente denigrante para quienes se entregan a ella vocacionalmente.

c) De nuevo independientemente de que yo niegue la mayor y rechace esta práctica, el hecho de que los sexenios por la actividad investigadora fueran tan restrictivos provocó un profundo desánimo. Que los sexenios adoptasen criterios más propios de las áreas experimentales y técnicas -las cuales por cierto contaban de antemano con revistas y foros para la divulgación de sus trabajos que ya se ajustaban desde antes a las nuevas exigencias requeridas-, lo que supuso, en definitiva, fue poner en valor sus modos habituales de proceder, y eso está bien. Pero al generalizarlos, ese principio de poner en valor lo propio se conculcó en gran medida en el caso de las ciencias sociales y humanas, las cuales ni trabajaban así (ni tienen porque hacerlo) ni contaban ni cuentan con suficientes revistas equivalentes, lo que condenaba y condena al ostracismo (léase destierro o exclusión forzosa) a cuantos hasta ahí habían servido y sobre los que la universidad se había apoyado; y conste que aún se apoya, por más que el problema de sus profesores parece ser el problema exclusivo de sus profesores y no el de sus Universidades.

d) Un problema que se multiplica pues los sexenios se han erigido por arte de birlibirloque en el criterio para todo. De modo que una evaluación opaca e injusta donde las haya prejuzga y condiciona cualquier otra aspiración. Pues, de hecho, concebidos inicialmente para evitar subir los sueldos a todos y con efectos exclusivos sobre el salario de algunos, pasaron sin ningún debate al respecto, a ser condición imprescindible para poder dirigir un proyecto de investigación, para formar parte de determinadas comisiones y tribunales, para aspirar (simplemente aspirar) a cualquier habilitación o acreditación. De modo que a día de hoy son muchos los damnificados por este proceder.

e) Muy relacionado con lo de los sexenios, podemos observar cuántas revistas, que fueron muy dignos instrumentos de difusión de nuestros trabajos, están en vías de extinción o ya han desaparecido, sin que nadie reconozca y agradezca el generoso esfuerzo de sus promotores y el valor intrínseco de los trabajos allí publicados. Unos y otros han sido arrojados al cesto de los papeles.

f) Otro tanto puede decirse de numerosos grupos de investigación que principalmente por una especie de darwinismo economicista simplemente desaparecieron. O bien que, en el menos malo de los casos, debieron integrarse, a veces forzadamente y perdiendo su identidad, en otros mejor organizados para la investigación, eso es 
posible, pero sobre todo mejor puntuados para lograr financiamiento externo. Siendo ésta una práctica a menudo cainita que se extiende, que discrimina entre grupos de primera y de segunda, de excelencia o no (cualquier cosa que represente eso y sin quitarle mérito alguno a los así reconocidos), y que lleva a que, habiendo cada vez más categorías, a los grupos de reciente creación todo les resulta cada vez más crudo.

g) Respecto a la reforma de las metodologías docentes en la universidad, francamente, hay un punto de partida en todo esto, que a pesar de que soy muy crítico con la práctica docente actual, a mi se me antoja obsceno. Y es esa idea, como si de un pecado original se tratase, de que todos los profesores (salvo raras excepciones) habrían abandonado por completo su responsabilidad en este asunto. Y aún habiendo mucho de eso, es verdad, ese no puede ser el punto de partida porque denigra injustificadamente a todo el colectivo de profesores que, según parece, seríamos pésimos docentes, es decir, culpables hasta demostrar lo contrario.

h) Por si fuera poco, todas estas prácticas se reproducen miméticamente en buena parte de las comunidades autónomas, lo cual, además de duplicar los procesos evaluativos, supone que tanto por el modo como se desarrollan como especialmente por las consecuencias que tienen (a nivel de salarios y de condiciones de trabajo), se generen agravios comparativos muy notables entre las universidades españolas.

i) Ante todo lo cual hay un colectivo que resulta ser especialmente vulnerable. Me refiero al integrado por muchos y muy jóvenes investigadores, que aún siendo ayudantes o incluso becarios asumieron solidariamente una buena parte de la carga docente de sus departamentos, que tras años de denodado empeño y con notable rigor defendieron sus Tesis obteniendo la máxima calificación, que han salido al extranjero, que son el apoyo fundamental de los grupos de investigación a los que pertenecen (sin ellos nada funciona), que han publicado en sus escasos años de vida entre nosotros un buen número de artículos como mínimo correctos (claro que generalmente en revistas indexadas pero no "de impacto"), y que como recompensa a su buena disposición se les tiene permanentemente en vilo, se les marea y desespera tanto con las fechas de las convocatorias para la acreditación como de la resolución que las agencias autonómicas manejan a su antojo, se les niega la acreditación para ser ayudantes doctores (sólo eso), y en definitiva se les pone a las puertas de la calle.

j) Finalmente, en este marco, se han legitimado procedimientos de evaluación de la docencia de los profesores por los estudiantes que resultan lamentables tanto metodológica como conceptualmente, pues consagran al tiempo que confunden la mera satisfacción de éstos como categoría que define la calidad docente (y no importa lo bien parados que salgamos).

Como consecuencia de todo ello, yo resumiría la situación respecto al estado de ánimo de los profesores de este modo: Que se comenzó ofendiéndonos a todos por lo de la endogamia, por cierto $\sin$ que apenas nadie reaccionara (¿merecíamos tener tan mala conciencia?), y ahora a muchos (a demasiados) se nos hace sentir que somos una especie de menesterosos abocados a la sopa boba. Y es triste. Aunque no tanto como el espectáculo de vernos competir -interuniversidades e interfacultades- cual supermercados por los clientes, o entre compañeros, cual brokers por un puñado de acciones (proyectos, cualificaciones, etc.).

Lo que ya no se -supongo que porque no los frecuento- es si habrá quien esté encantado y que disfrute de este modo de proceder. Supongo que sí. Me temo que sí. Y conste que he dicho "disfrutar", que no es lo mismo que entrar forzadamente por el aro.

\section{La presión burocrática:}

Tengo para mí que cada vez más nos pasamos más tiempo informando sobre nuestras respectivas actividades y cubriendo para ello numerosos impresos de control para múltiples servicios y agencias, pues ahora todo el mundo vigila a todo el mundo. Que ya no es suficiente por tanto con que hagamos cosas, sino que además debemos anotarlas, a menudo en aplicaciones informáticas que frecuentemente se me antojan que han sido concebidas por alguien que ha disfrutado pensando en cómo iba a volverme loco. Que trabajamos horas y horas para una burocracia de administrativos anónimos pero que, a la postre, son los que van a permitir que lo que sea 
que presentamos o pedimos (proyectos, sexenios, etc.) llegue a manos de nuestros pares a los que en principio sí les reconoceríamos capacidad bastante para valorar la relevancia del contenido (no sólo el formato) de nuestras aportaciones.

Véase, sin ir más lejos, como paradigma de ese burocraticismo abusivo el nuevo sistema de acreditación que viene a reemplazar a las habilitaciones (las cuales, por su parte, pronto se evidenciaron más caras, más complejas organizativamente y no menos sesgadas que los sistemas de oposición anteriores).

$\mathrm{Y}$ es que esto de cumplimentar archivos e impresos son horas y horas de árido trabajo, sin ayuda, a menudo contra reloj, que se hurtan al estudio y a la investigación, y que provocan una muy frustrante sensación de pérdida de tiempo.

Insistiendo en esto, yo me imagino -incluso prevengo- que si hay en algún lugar algún colega que se encuentre en ese trance y, además, colabora generosa y activamente en el esfuerzo de su facultad por cubrir formalmente y satisfacer en el fondo todos los criterios para el reconocimiento de sus titulaciones conforme al modelo oficial para la verificación de los títulos universitarios, ese colega habrá alcanzado el paroxismo; con grave riesgo de apoplejía.

Con el agravante, añado, de que todo eso se realiza, sin que ninguna autoridad académica reconozca y valore el esfuerzo de manera independiente al éxito que logre en esas dos empresas. Si le sale bien -se dirán-, lo rentabilizamos y si no, seguro que no era el indicado, habrá que cambiarlo. A mucha gente que conozco este proceder de "sus" autoridades le resulta muy crudo. Es natural.

El saldo final de todo esto me sugiere que, como en el caso de los estudiantes, no se ha tratado bien a los profesores, no con el respeto y el tacto debido para que se sintieran implicados en la tarea, para que la hicieran suya y se sumaran al esfuerzo de adecuación al EEES. Diría que la motivación de logro negativa no ha servido para lo que se pretendía, no al menos de momento; es cierto que mucha gente rumia su infortunio (no me dieron el sexenio, la habilitación, la acreditación, el proyecto, lo que sea), pero el temor al fracaso no ha funcionado: el plan de estimularlos espoleándolos y aguijoneándolos haciendoles que deseasen evitarse la humillación de un no, ha hecho sangre sí, pero se ha evidenciado como un mal sistema de incentivos. Y adviértase que digo "incentivos" no prebendas, y que incentivo es según el diccionario de la Real Academia lo "que mueve a desear o hacer una cosa; estímulo".

Quizás podrían haber ensayado otro sistema de incentivos que apostase por la versión positiva de la motivación de logro, aquella que refuerza con humildes éxitos los pequeños avances durante un proceso que va cada vez más a mejor y no a peor. Pero no ha sido así hasta ahora, aunque puede cambiar.

Mientras y salvo excepciones, la consecuencia es que en mchos, demasiados casos, todo quedará en un cambio meramente cosmético del asunto. Se adoptan nuevas palabras y formatos pero se seguirá haciendo lo mismo.

$\mathrm{Y}$ conste que aún estaríamos a tiempo de evitar algo así.

¿Qué acontece con la interacción entre profesores y estudiantes? Singularmente a la luz de la especial incidencia que tienen las tecnologías de la comunicación.

Quizás resulte este un asunto menor si lo comparamos con los otros que destaco en estas páginas; quien sabe ni siquiera es un problema, y bien al contrario es para muchos una oportunidad. Pero a mí me inquieta y deseaba comentarlo.

$\mathrm{Me}$ refiero a la comunicación profesorestudiante fuera del espacio de aula, en ese tiempo que convencionalmente denominamos horario de tutorías.

De partida me sitúo en una universidad presencial, que son la mayoría de las universidades españolas. Es cierto que esa tradición presencial se configuró in illo tempore cuando la práctica totalidad de los estudiantes universitarios no se dedicaban a ninguna otra cosa más que a estudiar (supuestamente). Estudiantes a tiempo completo, se decía. Pero eso cambió progresivamente desde finales de los setenta del siglo pasado, se amplió la tipología de los estudiantes universitarios a jóvenes que necesitaban trabajar y a mayores que debían simultanear su estudio con otras obligaciones de todo tipo. Así, paradójicamente, las matrículas crecían pero las aulas se vaciaban. 
Junto a eso, cada vez más estudiantes de los que sólo se dedican a estudiar optaron también por dejar de acudir a las aulas; la mayoría de manera selectiva, es decir, iban a las necesarias (convenientes, interesantes) o a las inevitables (por algún sistema de control y de censura) pero no a todas, y otros de manera total e indiscriminada las abandonaron para siempre excepto para acudir a los exámenes.

Y el caso es que las universidades presenciales no reaccionaron ante este hecho. Las disposiciones adoptadas son tan reglamentistas (solicitud justificada al Decano conforme al Reglamento de Régimen Interno del Centro para la exención de docencia) que existe como un acuerdo tácito para soslayarlas. Pero además, en estas circunstancias, son multitud los profesores que no saben con exactitud si los alumnos tienen el derecho y el deber de acudir a clase o sólo el derecho. Muchos no salen de su asombro cuando se encuentran que sí, en efecto, también tienen el deber pero eso no les exime del derecho de presentarse al examen, lo cual supone en la práctica una contradicción $\mathrm{y}$ en consecuencia obliga a algunos profesores a arbitrar medidas que les permitan discriminar entre asistentes y no asistentes.

La consecuencia de todo esto es que sin mejores posibilidades de encuentro la interacción personal profesor-alumno no se produce.

Por otra parte, las valoraciones de los estudiantes respecto a las tutorías nos indican que, al menos para ellos, dejan mucho que desear. Es posible, por supuesto, que responda a un prejuicio pues incluso los que aceptan no haber acudido nunca o casi nunca las valoran mal. Por eso ya ni van, dicen. Pero los que sí lo hacen, tampoco las valoran bien. Como ya dije antes el incumplimiento por los profesores de sus horarios es muy elevado, $y$ el sentido para el que se emplean es muy restrictivo, básicamente para revisar exámenes y pocas veces (muchas menos de las deseables) para recibir orientación previa a los mismos. Además, el clima en el que se desarrollan no facilita la comunicación, si no es abiertamente hostil puede ser abusivamente jerárquico o condescendiente $\mathrm{y}$, si no, generalmente condicionado por las prisas y las interrupciones. Si se midieran los tiempos en los que habla cada uno, el profesor consume el noventa por ciento. Todo, pues, parece indicar que no es la mejor situación para el diálogo.

Inasistencia a las aulas y dificultades para el diálogo en las sesiones de tutoría están en la base de una nueva forma de comunicación: la que se desarrolla a través del correo electrónico. Una vía de valor incuestionable en las universidades a distancia pero sobre la que tengo ciertas reservas en las universidades presenciales. Y no digo que no pueda ser un complemento para algún caso o circunstancia singular, pero no debería ser un sustituto de la interacción personal en las universidades presenciales como algunos parece que pretenden.

Adviértase que se da el caso de alumnos que comparten con sus profesores algunos minutos al entrar o salir del aula además del propio tiempo en la misma, o de alumnos que están en la Facultad cuando el profesor está en sus despacho, y esos mismos alumnos minutos antes o después le escriben un correo electrónico para consultarle o comentarle algo. Dicen que al hacerlo por ese medio se sienten menos cohibidos y que se expresan mejor. Ocurriendo con los profesores, por su parte, que varían mucho en su consideración: los hay que ni los atienden, lo hay que los leen pero después olvidan responder porque están muy ocupados o se les pasó el momento, los hay también que los responden todos, ya por extenso o ya telegraficamente, pero lo hacen. $Y$, en cualquier caso, los que sí los responden dicen que lo que más valoran de esta alternativa es la posibilidad que les ofrece de responderlos cuando les viene bien, generalmente más tarde, cuando encuentran el momento oportuno.

Pues bien, no acaba de gustarme. Principalmente porque eso no resuelvelos problemas, como mucho los palía. El incumplimiento del horario no se resuelve porque podamos responder al correo a las 12 de la noche o el Domingo a la mañana. Que el clima cohíba a los estudiantes no se resuelve porque estos eviten nuestra presencia comunicándose a través de la Red. Hay que crear una cultura que revalorice las tutorías, que supere el relajo existente de modo que su cumplimiento resulte moralmente tan exigente como el acudir a dar clase $\mathrm{y}$, por lo que parece, habrá que aprender a conversar: Saber escuchar, ponerse en su lugar, tener paciencia, moderar los gestos, en definitiva, afinar el tacto pedagógico. 
¿Habrá que organizar también cursos para esto? Los estudiantes pensando en algunos de sus profesores aseguran que sí.

\section{¿Qué acontece con el Currículo?}

Quede claro que comparto la necesidad de poner al día nuestras actuales propuestas. También que, a este nivel, encuentro en la coartada de EEES muchas oportunidades para la mejora de la oferta formativa de la Universidad. Pero en sintonía con el objetivo de identificar aquellos aspectos más problemáticos, destacaré lo siguiente: El desafío que supone adoptar un diseño por competencias. Y la tensión interna de los centros para elaborar los planes de estudio.

\section{El desafío que supone adoptar un diseño por competencias:}

Hay que partir de una reflexión sobre los Libros Blancos y su importancia. Finalmente parece que van a resultar de alguna utilidad. Considérese que si durante un tiempo parecía que en ellos se cifraba todo (era el tiempo del catálogo de titulaciones), hubo otro en el que pareció que iban a ser poco menos que olvidados (fue al inicio del momento en el que nos encontramos cuando se abandonó la idea del catálogo en beneficio de la del registro de titulaciones). Siendo así, los Libros Blancos representaron y aún suponen un serio condicionante - unos dicen que para bien, otros para mal- de cualesquiera nuevas propuestas curriculares.

Obviamente no puede ser de otro modo si tenemos en cuenta que el proceso se gestó de este modo: Una Agencia, la ANECA, contrata con las Universidades el desarrollo de un estudio de acuerdo con un protocolo que esa misma Agencia establece, lo que supone aceptar ciertas reglas de juego. El protocolo en cuestión tenía como objetivo la reordenación de la oferta universitaria para adecuarla al EEES, y en esa dirección establecía una metodología, denominada tuning, que traducido significa algo así como sintonización, armonización o tal vez mejor integración. Y, para ello, dirigía la mirada hacia determinados asuntos, obviando otros; tales asunto son: la estructura de los estudios en Europa y en España; la demanda de la titulación y la inserción laboral; la identificación y valoración de los perfiles y las competencias profesionales; y el establecimiento de criterios para la evaluación de la calidad.

Como consecuencias esencialmente técnicas de esa orientación encontramos: En primer lugar el Suplemento Europeo al Título (SET), que permitirá rastrear el proceso de formación seguido por cada estudiante habida cuenta de que su currículo de formación puede ser muy diverso en función de los múltiples itinerarios seguidos por el alumno para concluir sus estudios, puesto que ha podido cursar diferentes optativas e incluso realizar algún curso en otra universidad extranjera. Y en segundo lugar el Sistema de Transferencia de Créditos Europeos (ECTS), que contabiliza el número de horas dedicado por un estudiante a una materia de modo que pueda equipararse el trabajo realizado y así facilitar las respectivas equivalencias y el reconocimiento mutuo.

Ahora bien, la más relevante consecuencia de adoptar la metodología tuning ha sido y es, sin duda, la propuesta de diseñar y desarrollar un currículo basado en las competencias. El problema es que al respecto surgen muchas dudas y objeciones que generan un intenso debate - en el que me voy a detener ahora-, sobre la oportunidad de adoptarlas como guía y criterio de la función formativa de la universidad.

En esa dirección, quizás no sobre recordar:

-Que el concepto de competencia tiene su origen en trabajos de la Psicología industrial y organizacional norteamericana de finales de la década de 1960 y principios de 1970.

-Que el interés en las organizaciones se ha ido trasladando desde los puestos de trabajo, como elementos fundamentales, a las personas y a las competencias que estas aportan.

-Que esto obedece a un cambio de cultura que se concreta en que las personas han pasado de ser vistas como un coste que es preciso minimizar a ser entendidas como el principal recurso con que cuenta la empresa y que, por tanto, es preciso optimizar para que aporte todo su potencial al desarrollo de la misma. Y de ahí la proliferación de Departamentos de Recursos Humanos.

-Y que, finalmente, se dice que "posee competencias profesionales quien dispone de los conocimientos, destrezas y actitudes necesarias para ejercer una profesión, puede resolver problemas profesionales de forma autónoma y flexible y está capacitado 
para colaborar en su entorno profesional y en la organización del trabajo (Bunk, 1994, en Gil Flores, p. 84).

Ahora bien, sabido esto, me viene a la memoria lo que con su habitual fina e inteligente ironía dijo recientemente José Gimeno Sacristán en un acto en nuestra Facultad en Santiago de Compostela: Yo se, dijo, que existen las competencias porque soy capaz de identificar a mucho incompetente, pero si me piden que diga cuáles son para definir un plan de estudio, todo eso es mucho más complicado. Me pregunto, añadió, si podemos hacer un catálogo de conocimientos, que parece que sí pues tenemos una larga experiencia, pero si además es posible hacerlo de motivos, de rasgos de carácter, de concepto de uno mismo, de actitudes, de valores, de capacidades cognoscitivas y de conductas que pueden ser asociadas al desempeño excelente en un puesto de trabajo. Con lo que dejaba traslucir que ese empeño quizás puede ser excesivo y conducir a una trampa ${ }^{1}$.

Esa es pues la primera dificultad con este asunto de las competencias. Que se agranda a la vista de la ingente tarea que supone identificarlas, y después acertar en su selección y formulación. Pero además, resta por hacer una tarea extremadamente compleja como es aprender a evaluarlas, de modo que no se reduzcan a una mera relación de conductas operativas que ignoren su carácter complejo y con ello desvirtúen su sentido formativo.

Claro que, ante reservas tan justificadas no falta quien se pone a andar para hacer camino, como es el caso siempre de Miguel Zabalza, quien sugiere superar el dilema planteándose el problema en términos de ganancias para los alumnos. Y, en esa dirección, pregunta a los profesores: ¿qué ganan vuestros estudiantes tras estar con vosotros el tiempo que dura vuestra asignatura? ¿en qué han mejorado? Saben más cosas - dicen unos-, saben hacer cosas que antes no sabían. Y otros entran en cuestiones más cualitativas: piensan mejor, saben aplicar lo que estudian a casos, son más reflexivos, trabajan mejor en grupo. De manera que es ahí, sostiene Zabalza (2008), donde podemos concretar las competencias, tanto generales como de saberes, de valores $\mathrm{y}$ actitudes relevantes.

\footnotetext{
${ }^{1}$ Por cierto que desde que escribí esto, el Prof. Gimeno Sacristán ha publicado un libro, compilado por él, titulado, precisamente: Educar por competencias, ¿qué hay de nuevo" (Morata, Madrid, 2008).
}

Y está bien, quizás en efecto se pueda resolver así el problema. No obstante, confieso seguir teniendo ciertas reservas. Más aún si pienso que mucho antes de entrar en la reflexión sobre qué competencias, es probable que buena parte del profesorado no haya entendido correctamente siquiera lo de los ECTS. Sospecha que se hace más intensa cuando uno considera que puede suceder que lo acometamos de la misma manera frívola como resolvimos en su día el paso de las cinco o seis materias clásicas anuales a nuestro actual sistema de créditos. De tal modo que, si todo se reduce una vez más a un forzar las cosas para que de manera comprimida entre en menos tiempo la misma cantidad de materia, tal proceder haría inviable, como lo hace ahora, el desarrollo de un aprendizaje autónomo y con él todas las demás competencias. Por eso, me temo, quizás estemos construyendo una ambiciosa propuesta educativa sobre unos cimientos muy poco sólidos. Y el caso es que todo esto se ha puesto en marcha ya este curso 2008-09 y generalizará el siguiente; lo que supone que tendremos que aprender sobre la marcha mediante el ensayo y (mucho) error, una vez más.

\section{La tensión interna de los centros para elaborar los planes de estudio.}

En otro sitio (Trillo, 2008) he llamado a esto el Norte porque polariza el compás: En efecto, al final con lo que nos encontramos es con una nueva reforma de los planes de estudio de las diversas titulaciones. Muchos ya vivimos varias reformas, así que sabemos de qué va. El problema es la memoria colectiva que nos ha quedado de todo aquello. La convicción de que al final este asunto se resuelve mediante acuerdos a cara de perro entre grupos de presión que se identifican con las áreas o los departamentos (cuya esclerosis es la peor herencia de la LRU). La posibilidad de que una amplia mayoría o una hábil minoría consiga imponer o hacer valer una cultura que logre subordinar cualquier interés inmediato y espurio al objetivo común de diseñar el mejor plan de formación para los estudiantes, teniendo para ello en cuenta las necesidades de la sociedad en la que han de ejercer, suele ser valorado con escepticismo como una propuesta ingenua. Y, nos guste o no, ese es el caldo de cultivo del que partimos, como consecuencia de la memoria 
que guardamos de viejos vicios cometidos. Este es el ser. El deber ser es eso tan ingenuo que he mencionado y que requeriría algo así como una puesta a disposición de los respectivos centros de cualesquiera supuestos derechos adquiridos sobre la docencia por los profesores, además de una firme voluntad compartida por fortalecer el centro (Facultad, Escuela Superior) como garante último de las titulaciones que imparte, y al que se subordinan de buen grado los departamentos. Así las cosas, no es la titulación para uno, sino que es uno (todos) para la titulación.

¿Algo más? Seguro, pero para empezar habría que compartir algo así, y lo que me pregunto es ¿qué se ha hecho de manera decidida y efectiva en esa dirección? Bueno, no tengo información de primera mano de la mayoría de las titulaciones pero a partir de aquellas de las que sí he tenido noticia, lo que parece que ha sucedido recientemente y que está sucediendo es que las decisiones se han ido adoptando en un clima de abierta discusión, sin duda, pero sin tanta crispación y enfrentamiento como tal vez temíamos. No hablamos de una balsa de aceite pero tampoco de una guerra de guerrillas.

Sin abandonar el inevitable "qué hay de lo mío", una suerte de pragmatismo parece haberlo atemperado todo. El interés por no demorar la aprobación de las propuestas quizás ha servido para que se evitaran las inacabables discusiones de otras veces. Con todo, junto a eso, no desconsideraría como un elemento determinante más el que a buena parte de los que más podrían pinchar y cortar en este asunto, todo esto les ha cogido ya mayores (sic), quizás más maduros o quizás más descreídos, no lo se, pero sí mucho menos ambiciosos y combativos.

Tampoco es nada desdeñable la influencia de los propios Libros Blancos y las actividades siguientes organizadas por las conferencias de decanos o afines y otras sociedades y asociaciones científicas. Todo eso supuso que ya se hubiera discutido mucho antes, de manera que ya había suficientes elementos de referencia sino compartidos sí al menos conocidos para acotar el debate. Desde otra óptica, todo ese trabajo previo si no devino en acuerdos sí generó un notable cansancio, lo que rebajó también la tensión del momento de su aprobación en las Juntas de centros respectivas.
Sea como sea, ahí estamos, aprobando los planes. Si bien la supuesta voluntad de aunar esfuerzos y de hacer efectivo el criterio de validación mutua manteniendo para ello un amplio corpus téorico de conocimiento común intercentros, parece que cede terreno a la heterogeneidad de la oferta como expresión de un originalismo en el que se confía como reclamo de los estudiantes y que como es lógico depende de los intereses particulares de los profesores de cada centro y a las que suelen limitarse sus posibilidades docentes. Siendo así, las supuestas líneas de especialización emergentes no vienen a ser más que la ratificación de los itinerarios que ya se ofertan en la actualidad, lo cual tiene dos lecturas posibles: o bien representa la posibilidad de consolidar las innovaciones más recientes o bien supone simplemente mantener lo que veníamos haciendo. Me temo que puede haber más de esto último.

\section{¿Quésucedecon los Centros? Especialmente respecto a sus recursos materiales y humanos.}

Brevemente: ¿Alguien sabe de algún lugar en el que se iniciaran las obras de acondicionamiento de nuestros obsoletos edificios para facilitar (y no impedir) la nueva metodología de trabajo que exige el aprendizaje autónomo de los estudiantes? ¿Cuántos saben lo que ese modelo de aprendizaje reclama a ese nivel? ¿En algún lugar algún Decano ha recibido un comunicado de su rectorado instándole a que le informe sobre las necesidades docentes (de plantilla, formación, recursos) para afrontar bien preparados y con optimismo (lo que es importante) las tareas de los nuevos planes de estudio el próximo 2009/10? No sigo porque la ironía se ha hecho sarcasmo y duele.

Pero lo cierto es que, como a nadie se le escapa, todo esto del EEES provoca un gran impacto en la organización interna de los centros académicos. El número de materias va a disminuir, los tiempos lectivos deben cambiar radicalmente, y en consecuencia los espacios deberán reestructurarse para acomodarse a esta nueva forma de vivir en la universidad distinta de la solitaria y gregaria toma de apuntes durante cinco o más horas seguidas, y que implica que los estudiantes puedan hacer la parte del trabajo que les corresponde entre ellos y al margen del profesor y del aula. 
"La arquitectura de Bolonia: el campus didáctico", así titulaba un breve artículo Pablo Campos Calvo-Sotelo, profesor de arquitectura de la Universidad CEU en el periódico El País del pasado 20 de octubre. Desde las clásicas reflexiones acerca de que el contexto educa porque transmite valores e incide en la motivación, resultan muy interesantes sus aportaciones en orden a superar la vieja concepción de los edificios como meros contenedores de aulas, lo que choca radicalmente con algunas de las iniciativas recientemente adoptadas en varias universidades, entre ellas la mía, de construir aularios, al margen de la idea de Facultad como un espacio que, entre otras cosa, "debe despertar sentimientos de pertenencia en el usuario". Así, sugiere cosas como la calle educadora para sustituir al pasillo convencional, e insta a que cambiemos las aulas tipo lección magistral para dar cabida a los seminarios, la tutoría en grupo, la puesta en común, el apoyo multidisciplinar, etc.

En definitiva, que aún queda casi todo por hacer en este sentido.

Sin embargo, mucho antes de la actual crisis económica ya se decía que todo este cambio debía ser "a coste cero", y se decía mientras por ahí afuera sonaban los bombos y platillos del I+D+I, que no es para la docencia, junto a las recriminaciones sobre el descontrol en el excesivo gasto de las universidades.

Por todo ello, mucho me temo que puedan fallar las infraestructuras y recursos de las facultades. Desde luego, si van a ser las mismas que tenemos actualmente, eso va a jugar claramente en contra de las nuevas propuestas de una enseñanza centrada en el alumno.

\section{¿Qué sucede con la Universidad?} Especialmente cuando la recreamos ubicada en el contexto socio económico y cultural de los inicios del siglo XXI

Conste que me habría gustado enredarme con alguna reflexión sobre su gobierno, cada vez más piramidal y centralizado en los equipos rectorales y menos colegiado; también sobre el modo casi sectario como los grupos organizados de profesores y estudiantes actúan imitando a los partidos con los que razonable o aviesamente se les identifica y, hasta en ocasiones, casi al dictado de los mismos; también sobre la escasísima participación de los estudiantes caracterizados por una especial anomia en el marco de la universidad (mayor que fuera de la misma); también sobre la proliferación de los Institutos a imagen y semejanza de sus promotores y que actúan en detrimento de las Facultades. Me habría gustado enredarme con estas cosas, evidentes, y denunciar que se vienen produciendo hace tiempo sin que nadie debata en ningún lugar sobre su oportunidad y conveniencia.

Algo que puede que suceda porque todo esto ha cogido ya mayores a buena parte de los profesores universitarios, especialmente a la mayoría de los actuales titulares y catedráticos entre los que, paradójicamente, están muchos de los combativos PNNs de antaño.

En cualquier caso, tampoco dispongo de tiempo para extenderme más, así que me voy a centrar exclusivamente en una reflexión sobre el sentido de la Universidad ante el EEES.

En esa dirección abordaré cuatro aspectos: ¿De qué Europa hablamos cuando la adoptamos como referente? ¿Por qué la idea del EEES se asocia sin cuestionar a la de la Economía del Conocimiento, hasta el punto de que ésta eclipsa a aquella? ¿Profesionalización y empleabilidad son lo mismo? ¿Cuál ha de ser la relación de la universidad con el Poder?

\section{¿De qué Europa hablamos cuando la adoptamos como referente?}

Europa es un valor hegemónico, de esos que pronto se asumirán sin pensar. Pero mientras no ocurra, algunos sabemos que hay más de una Europa posible. Hasta ahora se ha impuesto la del mercado común, con el euro como tótem, y cuyo principal objetivo es sumar capitales para hacerse valer en el concierto económico internacional. Constituir, sobre todo, un lobby (camarilla) de naciones para presionar a otras mientras se miran de reojo entre sí.

$\mathrm{Y}$ en esa dirección se han desarrollado tantas iniciativas legislativas para armonizar tantos asuntos complejos que hagan posible ese mercado como son el comercio, la moneda, las fronteras, la seguridad, la defensa, las relaciones exteriores, etc., que no es de extrañar que le llegue el turno a la cultura y a la educación y dentro de esta a la universidad. 
Pero, ojo, no tanto por la universalización del conocimiento, pues eso ya existía desde siempre: ¿o no es cierto, por ejemplo, que uno de los fundadores de la Universidad de Santiago de Compostela, el Arzobispo Alonso Fonseca III, era quien avalaba la publicación de los libros de Erasmo de Rótterdam, allá por el siglo XVI?

La razón, pues, es otra, mucho más pragmática y también más prosaica, como es el reconocimiento mutuo de los sistemas de acreditación respectivos para que ofrezcan garantías de una formación homogénea que propicie la libre circulación dentro de la UE de los graduados universitarios. Europa en fin es el objetivo general que ya casi nadie cuestiona y en ese marco debemos entender el objetivo más específico del EEES.

Objetivo atractivo sin duda, pero que, como casi todo lo que concierne a Europa, todavía resulta ser más el fruto de la voluntad política de nuestros legítimos representantes que de la vocación de sus representados. Las declaraciones de La Sorbona (1998), de Bolonia (1999), de Salamanca (2001), de Praga (2001) y de Berlín (2003) son declaraciones de los Ministros que además se presentan como incuestionables, lo que resulta excesivo pues como mucho pueden ser convenientes, pero, en mi opinión, incluso hoy en día (escribí esto por primera vez en Julio del 2006 y vuelvo a hacerlo en octubre del 2008) falta todavía el necesario debate al respecto en el seno de cada Universidad.

Me refiero al debate sobre la Europa de las Universidades, sobre lo que éstas pueden aportar a esa construcción de un marco europeo común, mediante la aportación de ideas que no necesariamente tienen que subordinarse a la Europa del dinero. Y eso es algo que tampoco se restringe a comentar el sistema de ECTS y cosas así que, aunque interesantes y necesarias, son en realidad secundarias.

¿Por qué la idea del EEES se asocia sin cuestionar a la de la Economía del Conocimiento, hasta el punto de que ésta eclipsa a aquella?

A pesar del tiempo transcurrido desde la eclosión (o erupción) del llamado espíritu de Bolonia y la convergencia (luego "adecuación") al Espacio Europeo de Educación Superior (EEES), no deja de sorprenderme que algo así pueda provocar percepciones tan enfrentadas: pues si unos lo consideran una fuente de inspiración para la innovación de las universidades y la mejora de la oferta pública abriendo lainstitución alas necesidades sociales, otros simplemente ven ahí una coartada para sojuzgarlas y para reducir drásticamente el gasto de esa oferta desmantelando buena parte de la misma en función de los intereses del mercado. De tal manera que, la inicialmente razonable propuesta de homologar las universidades para que se reconocieran mejor y se apoyaran mutuamente en el seno de la Unión Europea, para algunos se ha convertido de hecho en todo lo contrario, es decir, en un alevoso proceso de desregulación del sistema universitario público (al introducir criterios de la iniciativa privada), en un insultante proceso de desconsideración de sus tradiciones en función de supuestos mejores modelos foráneos (importados del mundo de la empresa), y en un agresivo proceso de exacerbada competitividad (que no es sinónimo ni garantía de competencia) según el clásico modelo del "todos contra todos".

¿Quién tiene razón? Mentiría si dijera que lo se, si bien, desde siempre me inclino más hacia los que denuncian la connivencia y subordinación de la universidad a intereses economicistas que resultan espurios a la misma. Algo que, de ser cierto, me confirmaría lo que ya presuponíamos cuando todo esto empezó: que afrontábamos un proceso de "reconversión" (no innovación) de la universidad, sólo que a coste cero (sin indemnizaciones ni prejubilaciones con las que muchos, por cierto, bromeaban al principio).

Ahora bien, al margen del acierto en la denuncia, lo que puede ser discutible, qué duda cabe que antes incluso es posible cuestionar la legitimidad de los que así pensamos para decidir por nuestra cuenta que esos objetivos son espurios a la Universidad.

Mi profesor y compañero, Miguel Zabalza (2008), sin ir más lejos, lo ha planteado con toda crudeza y seguro que hay muchos que piensan como él. En su opinión, lo que yo he resumido es un debate en el que no queda títere con cabeza y que le desazona. "Se trata - dice-, de una retahíla de afirmaciones que transmiten la impresión de que existe una especie de mano negra dirigiendo el mundo y llevándonos a todos, pobres tontos útiles, 
al huerto de sus intereses". De manera que, frente a estas críticas, se reacciona con la memoria de una "Universidad de los profesores" donde éstos, que se piensan a si mismos como mejores (más justos, más clarividentes, con mejor capacidad de juicios para orientar las cosas), vendrían a ser los llamados a determinar lo que le conviene a la sociedad que deba ser la universidad. Cuando, en realidad, lo que se preconiza, en su opinión, es una universidad para esa sociedad frente a la universidad de y para los individuos: en definitiva, una institución que no tiene una "misión "más allá de los usos terrenales, sino una institución a la que se le encarga un "servicio" (como la sanidad, la función pública, las instituciones culturales, etc.)

Y bueno, está bien, es una manera de verlo, pero otros pensamos de otro modo, y así lo haré explícito en el último punto de este apartado.

En cualquier caso, todos, sin duda, antes de abrazar cualquier modelo de universidad debemos hacer una exégesis del asunto para poder decidir con mayor y mejor conocimiento de causa. Y eso es lo que propongo a continuación.

Así las cosas, si consideramos las tradiciones universitarias revisadas por Bricall (1997) y por Michavila y Calvo (1998), lo que nos encontramos es con una evidente alteración de los referentes: ya no respondemos al estilo napoleónico de una universidad que era fundamentalmente docente aunque en su seno también se investigaba; tampoco al estilo anglosajón que pone el acento en el desarrollo personal del alumno para que alcance la formación más completa posible; mucho menos al modelo alemán, humboldtiano, que sostiene que las universidades deben organizarse sobre las bases de la libertad académica y la ciencia generada por los profesores de manera desinteresada y autónoma.

Sorprendentemente nos estaríamos aproximando, en cambio, al estilo de la antigua URSS y los por entonces llamados países del Este, en el que los ministerios ejercían la tutela sobre las distintas carreras de acuerdo con criterios de dependencia funcional. Sin demagogia alguna, eso es lo que deben pensar algunos consejeros del ramo de algunas comunidades autónomas.

Salvados, por el descenso de natalidad, del estilo de la universidad de masas que se extendió durante los años setenta del siglo pasado, desde los década de los ochenta sí hemos ido adoptando progresivamente un estilo que podemos llamar $<<$ neoliberal $>>$, según el cual los Gobiernos, en nombre de la sociedad y de las restricciones presupuestarias que impone la urgencia de atender a otras necesidades sociales, sugieren que la Universidad está gozando de privilegios excesivos y que es necesario frenar su financiación, instando a las misma a reemplazar en mayor o menor parte la idea de servicio estatal por la de adaptación a las demandas del mercado.

Un estilo que, por supuesto, suena ahora en el 2008 con mucha más fuerza, y si no véase lo que pasa en la comunidades de Madrid y parece que también de Valencia y que, salvo en las palabras y en el alcance de las consecuencias (pues el control económico de las universidades está transferido a las comunidades autónomas), no difiere de la idea expresada por la Ministra Cristina Garmendia acerca de que "no es coherente tener presupuestos expansivos en la universidad, por la crisis" (La Voz de Galicia, 24-X-08).

Según esto, lo que ya se veía en la década de los noventa se mantiene hasta nuestros días: esto es, que mientras la financiación se restringe las demandas aumentan. Todo el proceso de creación del EEES es, precisamente, un buen ejemplo de ello: más internacionalización, más diversificación, nuevas metodologías docentes, nuevas tecnologías e infraestructuras. $Y$ todo eso bajo dos nuevos focos de atención que parecen polarizar todas las miradas: la $<<$ calidad de la enseñanza superior $>>$ (cualquiera que sea su significado) por una parte y, por otra, su evaluación, concebida sobre todo como una actividad para rendir cuentas. Algo, por cierto, que puede poner en entredicho la propia autonomía universitaria.

De manera que, como resultado, nos encontramos ahora en una encrucijada:

Un camino conduce al estilo neoliberal puro y duro, que es aquél que dice que si la universidad no puede autofinanciarse que se apriete el cinturón. Y habrá que saber en qué consiste eso: si menos becas, si menos titulaciones, si menos profesorado, si ninguna nueva construcción.

El otro camino supone seguir una senda que es en realidad una versión más dulcificada de la anterior y que ha sido vista con especial optimismo 
por muchos en tiempos de bonanza pero que, quizás ahora se comprenda que no es la panacea de nada. Este camino se ha dado en llamar el estilo de las universidades emprendedoras. Expresión que algunos consideramos un eufemismo de empresa, y que ha hecho suya la supuesta nueva idea de la Economía del Conocimiento. Un planteamiento que básicamente supone obtener una rentabilidad económica del mismo.

Pero, me pregunto, ¿acaso el conocimiento generado y manejado por la universidad no ha beneficiado desde siempre a la que, para diferenciarla de la supuesta casta de los profesores, llamaré la sociedad civil? En fin, yo creo que es de justicia reconocer que son muchos los que pasaron por las aulas universitarias, los que se relacionaron con ella o los que mucho más indirectamente se beneficiaron de la actividad generada por ésta. Así, pongo por caso, que si un departamento universitario de microbiología identifica un virus que es preciso aislar para evitar una epidemia, todos los que no enfermamos gracias a las medidas adoptadas para evitar lo que desde la universidad se había advertido, somos deudores de ese hallazgo y deberíamos estar agradecidos de que exista gente que se dedica a investigar esas cosas. De este modo, lo único que es nuevo es que para poder pagar parte de la factura de este servicio público ahora se pretende que la universidad cobre por sus servicios y se lleve una parte del potencial negocio (por ejemplo, el farmacéutico, pongo maliciosamente por caso). Se le llama transferencia de conocimiento, pero es eso. Y ahí radica todo.

La Ministra Cristina Garmendia lo ha dicho sin tapujos: "La financiación privada tiene dos vías, el mecenazgo y la contratación de servicios de $\mathrm{I}+\mathrm{D}$ o a través de acuerdos con pago de royalties" (La Voz de Galicia, 26-X-08). ¿Cabe alguna duda sobre la orientación netamente mercantil de todo esto?

Y sí, a algunos no nos place la idea. Y no precisamente para poder mantener una situación de privilegio, como sugieren nuestros detractores, sino porque nuestra función social es hacer todo eso de manera altruista. Y también, cómo no, porque de otro modo, quién lo duda, no habría de pasarmucho tiempo en el que se prescindiera de saberes específicos de las ciencias sociales y de las humanidades difícilmente rentables económicamente. De las que se dirían, tienen mérito pero escaso valor. Y eso sencillamente no es aceptable para los que compartimos con Don Manuel Alvar que "el mundo [es] algo más que una factoría donde algo o mucho se compra o se vende, pues el estudio de lo que se reputa inútil nos hace ser otra cosa que mercaderes, perdidos en la circunstancia de su momento y limitados a un ahora que ni transciende ni comprende". Por más que no resulte fácil ni cómodo disentir de los cánones vigentes.

\section{mismo? \\ ¿Profesionalización y empleabilidad son lo}

Sostengo que no. Y eso no significa que ignore que hay muchas personas que cifran precisamente en sus estudios universitarios sus expectativas de primer acceso al mundo del trabajo, que vienen a la universidad para que se les prepare de forma tal que puedan emplearse. Pero, de ahí a admitir que la preparación para el mundo del trabajo eclipse en buena medida cualesquiera otras funciones de la Universidad, hay un paso que me resisto a dar.

$\mathrm{Y}$ es que esta perspectiva, con su discurso sobre perfiles y competencias profesionales, es probable que nos centre en la realidad y nos aleje de la pendiente de una formación meramente especulativa ( $\sin$ praxis) -a la que por otra parte estamos tan acostumbrados-, pero ello no nos exime de considerar que, tal vez, entender la adaptación de la universidad a la sociedad como una mera coordinación de sus salidas con entradas en empleos bien definidos, en definitiva que la profesionalización derive en empleabilidad, supone subordinar groseramente los fines de la Universidad a los intereses del Mercado.

Por supuesto, como advierte Zabalza (2008), no hay razones para contraponer un modelo de perfiles profesionales y saberes útiles al de una universidad del conocimiento y de la sabiduría y, de acuerdo con eso, no hay razones tampoco para contraponer formación y empleo. Ser competente para desempeñar un puesto de trabajo no está reñido con una buena formación, sino que la requiere. Por ejemplo, formación crítica, reflexiva, basada en la responsabilidad personal y en la ética, atenta a la multiculturalidad, orientada a la colaboración y el trabajo en grupo. Todas ellas son competencias generales del EEES y están bien. 
Pero, frente a eso, también hay evidencias de que lo que importa es la tecnología, no la conciencia crítica; la preparación para un oficio, no el rigor científico; la competencia tecnológica, no el talante intelectual. En definitiva, que el papel de la universidad como centro de una elevada educación y de una ética humanística está en franca quiebra" (GARCÍA GUAL, 1990). Y si es esto lo que ocurre, lo que yo creo es que sobra entreguismo al Sistema.

\section{Poder?}

\section{¿Cuál ha de ser nuestra relación con el}

Hace años que escribí esto (TRILLO, 2000) pero me ratifico: Contra lo que pudiera parecer no es sólo una cuestión funcional acerca del tipo de relaciones; tal y como yo lo veo es más una cuestión de valores: de los valores que la Universidad quiere darse a si misma (si es que quiere todavía). $\mathrm{Y}$, en esa dirección, parece estar claro, al menos para mi, que la Universidad no puede ser sólo contingente a la demanda social, y de ese modo puramente mimética en su arquitectura moral, sin que eso signifique tampoco que puede encerrarse en sí misma. Debe servir, por el contrario, a la sociedad, pero esto no quiere decir plegarse a las exigencias inmediatas y a menudo circunstanciales de la clase política o empresarial por más legitimadas que estén ambas para plantear sus demandas. En este sentido, cabría recordar aquí aquello de que los ministros pasan (también los rectores), pero la Universidad sigue.

El sociólogo Alain Touraine con motivo de su intervención en unas jornadas sobre $<<$ La Universidad y su futuro $>>$ celebradas en Santiago de Compostela en abril de 1996 sugirió -si no le entendí $\mathrm{mal}^{2}$ - (aunque escéptico sin duda), la posibilidad de que la Universidad jugase un papel de mediación entre el sistema económico y el sistema social, toda vez que la religión y la política habían sido ampliamente superadas por el capitalismo financiero (mucho más crudo que el comercial o el industrial por la coartada del anonimato). La posibilidad, en suma, de ser una voz discrepante que mediante un discurso científico y crítico sirviese de contrapunto

\footnotetext{
${ }^{2}$ Le cito directamente de unas notas manuscritas tomadas durante aquellas jornadas por lo que, a fuer de sincero, no sabría decir hoy qué es literal suyo y qué interpretación mía.
}

al poder económico; el cual ante la ausencia de otros canales de mediación, derivaría fácilmente hacia el autoritarismo: producir o morir. La vocación al fin, añadiría yo, de que la Universidad actúe como inquietante y contumaz Pepito Grillo.

Siendo así, no estamos lejos de lo que decía Bloom (1989):

No es, por lo tanto, la sociedad masificada y manipulada por los políticos quien debe orientar a la institución universitaria; sino que la Universidad debería mantener su autonomía frente a las presiones de ese entorno. Tampoco debe ajustarse a los requerimientos que la sociedad le impone como su única aspiración. Debe mantener, por encima de esos ajustes y esos servicios, su tensión cultural, crítica y moral. La Universidad debe ofrecer una compensación a aquel rigor intelectual que falta en la calle.

Ni tampoco de lo que reclamaba García Gual (1990):

[...] la Universidad ... es algo más que un centro de preparación para futuros empleos, más que una máquina de dispensar títulos especializados, más que un repertorio de estudios dispersos y concretos. Como conciencia crítica necesita una cierta distancia y una perspectiva sin agobios ...Lo contrario es una institución encapsulada, pendiente de su adaptación a instancias ajenas, con menguadas y embotadas facultades. (p.55).

No obstante, no debemos hacernos ilusiones. Michael Apple, con motivo de su participación en A Coruña en 1993 en el Congreso $<<$ Volver a pensar la educación $>>$, hizo una clara denuncia del sistema universitario estadounidense por cuanto se dejaba ir por la pendiente de la subordinación a los intereses de sus patrocinadores, hasta el punto de que se renunciaba a la investigación y a la docencia que según estos mismos los contrariara. Y siendo así, tal pareciera que la ironía de Aranguren (1973) se trocase en profecía: "Gastar dinero en centros de agitación ¡ qué disparate!” (p.51)

Sin embargo, en este marco, permítaseme introducir un comentario a las declaraciones que la Ministra de Ciencia e Innovación, Dña. Cristina Garmendia Mendizába, ha realizado a través de una entrevista que reproduce La Voz de Galicia del Domingo 26 de octubre del 2008. Acusa la Ministra: "La Universidad no ha sabido reinventarse al ritmo de la sociedad". 
Y yo me pregunto ciñéndome al ámbito económico en el que sitúa la declaración de la Ministra: Y si lo que ocurre es que la sociedad se ha desquiciado, como pone de manifiesto la actual crisis financiera, ¿debería desquiciarse también la Universidad para estar a la altura de los tiempos?

\section{A modo de Epílogo}

Porque no hay conclusión posible.

El caso es que todo podría haber sido mucho más sencillo y hasta placentero.

No creo que nadie negase la conveniencia de la homologación universitaria a nivel internacional.

Tampoco que los profesores necesitaban una actualización de sus metodologías docentes, especialmente para promover un aprendizaje autónomo por los estudiantes.

Además, con todo aquello de los Libros Blancos se había alcanzado ya un amplio acuerdo (por activa o por pasiva) acerca de la conveniencia de establecer un catálogo de titulaciones y unas directrices generales comunes sobre, al menos, el sesenta o setenta por ciento de sus contenidos.

Así las cosas, y a pesar de la bravata de que todo habría de realizarse "a coste cero", tal pretensión resultaba y resulta tan disparatada que, en realidad, muchos confiábamos en que los mismos datos sobre la evaluación de las titulaciones que fueron dados por buenos en la en el marco del Plan Nacional de Evaluación de la Calidad Universitaria, hiciera ver con fundamento y mesura las necesidades materiales y humanas (algunas acuciantes) que era preciso atender para acometer el cambio que el EEES reclamaba.

En ese contexto, pienso (y me lamento), hubiera sido tan razonable que en vez de agredir al profesorado se fortaleciese su autoestimación. Habría estado tan bien que se incentivase su actividad mediante la puesta en valor de sus realizaciones, la recalificación sin complejos de sus revistas y demás publicaciones, el aprecio por sus congresos, el agradecimiento por sus actividades de extensión social. Pero no fue así. Primó la fiscalización,

Del mismo modo, hubiera sido tan necesario que se divulgase ampliamente esta iniciativa, que se generasen foros de debate para todos y no sólo para las autoridades académicas. Pensando en los estudiantes -que ahora se movilizan-, habría sido tan sencillo respetar su derecho a saber sobre lo que les depara su inmediata vida académica.

Pero no, individuos concretos y sus camarillas, gente que puede nombrarse y que habitó y aún habita en el MEC, las Consejerías de las Comunidades Autónomas, la CRUE, y algún Colegio Profesional, optaron -para evitarse problemas y/o soltar lastre-, por el oscurantismo, por los bandazos, por el burocraticismo y por el rendimiento de cuentas.

Siendo así, todo eso provocó una descapitalización radical de la imprescindible motivación que se requería.

¿Qué más puedo decir? Una lástima.

Especialmente porque se llevará adelante sí, con cumplimiento: el cumplo y miento, que tantas veces denuncia mi amigo y colega el Prof. Xulio Rodríguez.

\section{Referencias}

ANECA. Libro blanco de pedagogía y educación social. 2004. p.145. Disponible em: http://www.aneca.es/var/ media/150392/libroblanco_pedagogia1_0305.pdf

ARANGUREN, J. L. El futuro de la universidad y otras polémicas. Taurus. Madrid, 1973

BLOOM, A. El cierre de la mente moderna. Plaza \& Janes. Barcelona, 1989.

GARCÍA GUAL, C. Sobre la degradación de la educación universitaria. En: Claves de Razón Práctica, 2, 1990. p.52-56.

MiCHAVIla, F.; CALVO, B. Propuestas para una política universitaria. Madrid: Síntesis, 1998.

TRILLO, F. As atitudes dos estudantes. Um indicador da qualidade universitaria. Em: Trillo, F. (Coord.). Atitudes e valores no ensino. Piaget. Lisboa, 2000. p.215-262.

El reto de las titulaciones de educación. Otra crónica a 7 de marzo de 2008. Educación XX1, v.11, p.1941, 2008.

ZABALZA, M. A. El espacio europeo de educación superior: innovación en la enseñanza universitaria. Innovación Educativa, v.18, p.69-95, 2008.

Recebido para publicação: 14/05/2012 Aceito para publicação: 04/06/2012 